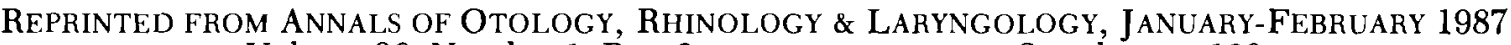 Volume 96, Number 1, Part 2 Supplement 128 COPYRIGHT 1987, ANNALS PUBLISHING COMPANY
}

\section{CLINICAL RESULTS FOR POSTLINGUALLY DEAF PATIENTS IMPLANTED WITH MULTICHANNEL COCHLEAR PROSTHESES}

\author{
A. M. Brown, BSc, Dip Aud; R. C. Dowell, BSc, Dip Aud; G. M. Clark, PhD, FRaCS
}

Clinical results for 24 patients using the Nucleus 22-channel cochlear prosthesis have shown the device to be successful in presenting amplitude, fundamental frequency, and second formant information to patients with acquired hearing loss. For all patients, this has meant a significant improvement in their communication ability when using lipreading and some ability to understand unknown speech without lipreading or contextual cues. Approximately $40 \%$ of patients are able to understand running speech in a limited fashion without lipreading, and this ability has been evaluated using the speech-tracking technique for a number of patients. Many patients are able to have limited conversations on the telephone without using a special code. Although the prosthesis has been designed with the presentation of speech signals in mind. recognition and discrimination of environmental sounds has also been very encouraging with patients scoring $70 \%$ to $80 \%$ correct for closed set environmental sound testing. Follow-up testing has indicated that the ability to understand open set speech without lipreading continues to improve up to at least 12 months postoperatively. Open set sentence test results improved from an average of $20 \%$ at 3 months to $40 \%$ at 12 months

A total of 30 postlingually deaf adults have undergone cochlear implant surgery in Melbourne since 1982. All have received the Nucleus multiple-channel cochlear prosthesis.

The clinical results for 24 of these patients are being reported in this paper. (The remaining six were excluded either because they were non-English-speaking or because they had not completed the postoperative rehabilitation program).

The cochlear implant has 22 electrodes, which are inserted into the scala tympani via the round window. The speech processor extracts the amplitude, fundamental frequency, and an estimate of the second formant frequency from the acoustic signal. The amplitude determines the current level, the fundamental frequency determines the rate of stimulation, and the second formant frequency determines the place of stimulation (ie, the electrode to be stimulated). More recently, the first formant frequency has also been incorporated into the speech-processing strategy.

A summary of the patients is given in Table 1. All patients were profoundly deaf. None of the patients were found to obtain significant benefit from hearing aids and/or tactile aids, either in speech understanding or as a lipreading aid.

\section{TABLE 1. SUMMARY OF PATIENTS}

\begin{tabular}{|c|c|}
\hline Number of patients & 24 \\
\hline \multicolumn{2}{|l|}{ Age $(y r)$} \\
\hline Average & $5 !$ \\
\hline Range & $19-73$ \\
\hline \multicolumn{2}{|l|}{ Sex } \\
\hline $\mathbf{M}$ & 17 \\
\hline $\mathbf{F}$ & 7 \\
\hline \multicolumn{2}{|l|}{ Cause } \\
\hline Otosclerosis & 4 \\
\hline Meningitis & 3 \\
\hline Head trauma & 2 \\
\hline Chronic ME & 2 \\
\hline Ototoxic & 1 \\
\hline Meniere's & 1 \\
\hline Virus (unknown) & 2 \\
\hline Autoimmune & 1 \\
\hline Unknown (prognosis) & 8 \\
\hline \multicolumn{2}{|c|}{ Length of profound deafness ( $y r$ ) } \\
\hline Average & 12 \\
\hline Range & $0.6-42$ \\
\hline
\end{tabular}

\section{RESULTS AND DISCUSSION}

Speech detection thresholds were obtained preoperatively (with hearing aid) and postoperatively (with cochlear prosthesis). Preoperatively, the average was $65 \mathrm{~dB}$ sound pressure level (SPL) and postoperatively the average was $44 \mathrm{~dB}$ SPL. This was a significant improvement $(t=7.4$, $\mathrm{p}<0.001$ ). For many patients detection of speech at normal conversational levels was possible postoperatively, whereas preoperatively it was not.

The primary aim with the cochlear prosthesis is to provide auditory information that supplements visual cues obtained by lipreading, thereby enhancing the person's communicative abilities. The contribution of the cochlear prosthesis to speech understanding was assessed using the Central Institute for the Deaf, St Louis (CID) Everyday Sentences Test ${ }^{1}$ (consisting of open set unfamiliar material). The test is scored in terms of the percentage of key words correctly repeated. Referring to Table 2 , the average score when just lipreading was $53 \%$, and the average score when lipreading and hearing was $83 \%$.

One can also compare the patient's rate of communication with and without the cochlear prosthesis. This can be estimated using the speech-tracking procedure developed by De Filippo and Scott. ${ }^{2}$ In this procedure, the clinician reads aloud from a text. The patient is required to repeat this verbatim. If the patient misses a portion, a hierarchy of strategies is used by the clinician until a correct response is obtained.

The average tracking rate for patients when just lipreading was 16 words per minute, and when lipreading and hearing was 44 words per minute. This was a significant

TABLE 2. AID TO LIPREADING

\begin{tabular}{lc}
\hline \hline CID everyday sentences & Average $(\%)$ \\
(22 patients) & 83 \\
Lipreading and hearing & 53 \\
Lipreading only & \\
$(t=7.72, \mathrm{p}<0.001)$ & Average rate $(\mathrm{wpm})$ \\
Speech tracking & 44 \\
(24 patients) & 16 \\
Lipreading and hearing & \\
Lipreading only \\
$(t=12.5, \mathrm{p}<0.001)$
\end{tabular}


TABLF 3 OPEN SET SPEECH RECOGNITION WITHOUT LIPREADING

\begin{tabular}{lcc}
\hline \hline CID everyday sentences & Average (\%) & Range (\%) \\
(22 patients) & 18 & $0-58$ \\
Recorded presentation & 43 & $0-100$ \\
Live voice presentation & & \\
& & \\
Speech tracking & $25 \mathrm{wpm}$ & \\
$\quad$ Lipreading and hearing & $13-31 \mathrm{wpm}$ & \\
Range
\end{tabular}

improvement $(t=12.5, \mathrm{p}<0.001)$. The average increase was threefold.

A large proportion of the patients also exhibited some speech understanding without lipreading when using the cochlear prosthesis. With two exceptions, all patients recognized some key words in the CID Everyday Sentences Test. Of the two who did not, one patient had a very restricted system (as disease prevented the use of most of the electrodes) and the second patient was arguably on the borderline of being prelingually deaf, having become profoundly deaf at the age of 6 years. Referring to Table 3 , the average score was $18 \%$ for recorded material and $43 \%$ for live voice presentation. In a smaller number of patients, speech tracking was attempted using hearing only. For the seven patients in which this was attempted, an average tracking rate of 25 words per minute was obtained.

In general, all patients would both listen and lipread when communicating. However, the ability to understand running speech without lipreading enables a significant number of these patients to use the telephone for two-way conversations.
Although improved communication has been the major aim in the design of the cochlear prosthesis, awareness and recognition of environmental sounds is also an important feature. In addition to the more obvious benefits, there is an important psychological benefit in having a "link" with the auditory world, lessening the patient's feelings of isolation. Awareness of many environmental sounds was achieved using cochlear prosthesis with many of the common sounds (such as the telephone bell, the dog bark, and the kettle whistle) becoming easily recognized. A closed set Everyday Sounds Test was used to assess the patients abilities to discriminate environmental sounds. Patients scored an average of $75 \%$ correct (chance score was $20 \%$ ). This ability was relatively consistent among patients, with scores ranging from $60 \%$ to $93 \%$.

It is anticipated that continued improvements will be seen as the patients gain more listening experience. This hope is supported by the results of a 12-month follow-up study of 13 patients. The average open set speech discrimination score (using the CID Everyday Sentences Test) of these patients at 3 months postoperatively was $16 \%$. Twelve months postoperatively the average score was $37 \%$. The average improvement was $20 \%$ with the range of improvement varying from $0 \%$ to $44 \%$.

\section{REFERENCES}

1. Davis $\mathbf{H}$, Silverman SR. Hearing and deafness. New York: Holt Rinehart \& Winston, 1970

2. De Filippo CL, Scott BL. A method for training and evaluating the reception of ongoing speech. J Acoust Soc Am 1978:63: $1186-92$. 


\section{University Library}

\section{- M M N E R VA A gateway to Melbourne's research publications}

Minerva Access is the Institutional Repository of The University of Melbourne

Author/s:

Brown, A. M.;Dowell, R. C.;Clark, Graeme M.

Title:

Clinical results for postlingually deaf patients implanted with multichannel cochlear prostheses

Date:

1987

Citation:

Brown, A. M., Dowell, R. C., \& Clark, G. M. (1987). Clinical results for postlingually deaf patients implanted with multi-channel cochlear prostheses. Annals of Otology, Rhinology \& Laryngology, January-February, 96(1, part 2, suppl.128), 127-128.

Persistent Link:

http://hdl.handle.net/11343/27239 